\title{
Conservation Concern for the Deteriorating Geographical Range of the Grey Parrot in Cameroon
}

\author{
Simon A. Tamungang, ${ }^{1}$ Robert A. Cheke, ${ }^{2}$ Gilbert Z. Mofor, ${ }^{3}$ \\ Richard N. Tamungang, ${ }^{4}$ and Fritz T. Oben ${ }^{5}$ \\ ${ }^{1}$ Department of Animal Biology, University of Dschang, B.P. Box 146, Dschang, Cameroon \\ ${ }^{2}$ Natural Resources Institute, University of Greenwich at Medway, Central Avenue, Chatham Maritime, Kent ME4 4TB, UK \\ ${ }^{3}$ Geography Department, Higher Teachers Training College, University of Bamenda, P.O. Box 39, Bambili, Cameroon \\ ${ }^{4}$ Projet GEF/TRIDOM, Equipe National de Projet, B.P. Box 836, Yaounde, Cameroon \\ ${ }^{5}$ Department of Soil Science, FASA, University of Dschang, B.P. Box 222, Dschang, Cameroon
}

Correspondence should be addressed to Simon A. Tamungang; atamungang@yahoo.com

Received 23 June 2013; Revised 8 October 2013; Accepted 27 November 2013; Published 16 February 2014

Academic Editor: A. E. Lugo

Copyright (C) 2014 Simon A. Tamungang et al. This is an open access article distributed under the Creative Commons Attribution License, which permits unrestricted use, distribution, and reproduction in any medium, provided the original work is properly cited.

\begin{abstract}
The need for information on Grey Parrot distribution and vegetation associations for informed management and policy decisions was the basis for this study. A nationwide survey of the Grey Parrot population and habitat status was carried out, using questionnaire and point count methods. From the results, the extent of the contemporary range of the parrots was restricted to Southern Cameroon, which harbours the rainforest. Regional parrot population means ranged from 3,487 parrots in the Littoral to $1,351,275$ parrots in the East Regions. The extent of the contemporary range as a percentage of the whole country was $25.4 \%$ and as a percentage of the regions with rainforest was $44.5 \%$. The historic range of the bird has been reduced by over $55.5 \%$. Estimated percentage of forest lost per region ranged from $20.4 \%$ in the Centre to $57.1 \%$ in the East and South Regions. At a global level, Cameroon contributed 9\% to the total extent of the range of the Grey Parrot in Africa. The range is increasingly fragmented, contracted, and lost through land-based socioeconomic activities. These degradation pressures on the range called for urgent conservation considerations for long-term survival of the parrot species and its associated biodiversity in Cameroon.
\end{abstract}

\section{Introduction}

Forested landscapes support people, biodiversity and agriculture, industry, and climate, making them highly productive [1]. Forests have a value for all these categories, locally and globally. Cameroon's forests are among the most biologically diverse in the Congo Basin. Yet they are under rapidly increasing development pressures [2]. In the past 20 years, Cameroon has experienced a large demographic increase, which in turn has caused an increase in the use of forest resources. These factors have in turn led to an increased focus on expanding mineral extraction and industrial agricultural plantations in the country [1]. Furthermore, the rapidly developing urban areas need more land to meet their socioeconomic and basic living requirements.

Such rapid destruction of the rainforests has an alarming implication on both humans and wildlife [3]. The reduction of the carbon sequestration process can lead to climate change, overhunting, depletion of key seed dispersers, and disruption of food chains, which may also result in shifts in species abundance and composition [4]. The subtle and far-reaching effects of forest destruction are readily apparent [5]. Yet the survival of bird species depends on the level of exploitation of the forest, as the level of exploitation influences the response to population dynamics $[5,6]$. It is therefore important that forest conservationists understand the multiple perspectives 
and competing demands for the exploitation of the forest at all levels [7].

The Grey Parrot Psittacus erithacus is one of Cameroon's umbrella wildlife species whose major habitat type is predominantly the rainforest. It is one of the most popular and important avian pets in Europe, the USA, and the Middle East, owing to its longevity and unparalleled intelligence [8]. It has a large range in West and Central Africa, extending marginally into East Africa, with an estimated global distribution range of some $3,000,000 \mathrm{~km}^{2}$ [9]. From DNA studies, the African Grey Parrot is now recognised as comprising two species: the Congo Grey Parrot P. erithacus, which occurs from east of the River Comoé in Ivory Coast to Angola, and the western form (Timneh Parrot P. timneh), which is found at west of the River Comoé in Ivory Coast to Sierra Leone [10].

In Cameroon, data on the geographical distributions and ecological requirements of parrots are limited. At the same time, concerns about the potential impacts of habitat fragmentation, deforestation, and live parrot offtake for the pet trade are of increasing interest to ecologists, wildlife managers, and policy makers [11]. For these reasons, data are needed for informed decisions on the parrot and its range, to determine sustainable conservation strategies for its populations. The need for information on Grey Parrot distribution and vegetation associations in Cameroon for informed management and policy decisions formed the basis of this study [9].

\section{Materials and Methods}

2.1. Study Area Design. The overall study site design adopted for data collection was Stratified Random Sampling [12]. Stratified Random Sampling is the optimum survey design to use when there are two or more distinct habitats. This design was suited for this study because of the many varied ecoregions that give rise to varied vegetation types and the ten government administrative regions. For the purpose of easy demarcation of each stratum, the administrative regions of the country were chosen as strata, which were further subdivided into substrata using protected areas and important bird areas outside protected areas. A total of thirtytwo substrata were identified in the whole country in which all the ecological zones and administrative regions were represented. The historic range of the Grey Parrot was traced on the map by regions. The regions were further subdivided into substrata using 17 protected areas, 8 important bird areas (IBAs) outside protected areas [13], and 7 other sites where the parrots were known to occur. All ecological zones and administrative regions with Grey Parrots within them were represented (Figure 1).

A survey was carried out by a team on the ground in the study area from 2008 to 2011 involving collection of nationwide data on parrot population distribution, abundance, and vegetation associations. Two major methods (questionnaire and point count) were used for field data collection.

2.2. Questionnaire Administration and Focus Group Discussions. The research team was made up of five persons (two wildlife biologists, an environmental geographer, a rural sociologist, and a driver). Structured questionnaires (open and closed), personal interviews, and focus group discussions were administered to a cross-section of the rural population on aspects of parrot distribution, forest exploitation, and wildlife conservation activities.

2.3. Parrot Population Survey. Transects of $1 \mathrm{~km}$ length were randomly selected in each sample area and 10 paths were covered within them, contributing a total length of $10 \mathrm{~km}$ per site. We used the point count method to census Grey Parrots, a method widely used to sample bird communities in tropical forests and to calculate changes in bird abundance with time [14-17]. Point counts involve mainly visual and auditory detections of birds with fixed or unlimited radius plots $[15,18]$. Their efficiency and accuracy are influenced by observer effort, which may affect the information obtained such as species abundance [19-21]. If well spaced, a sample series of points in an area will provide more representative data than a few transects. The point count therefore has an advantage over transects, being easier to incorporate into a formal study design.

Each point consisted of a circle made up of two counting bands or radii [22]. The first band had a radius of $25 \mathrm{~m}(r$ $=0-25 \mathrm{~m})$. Any parrot that was detected outside the $25 \mathrm{~m}$ radius was recorded in the second band with its radius set as infinity $(r=25 \mathrm{~m}-\infty)$. It was assumed that as the radius decreased, the probability that Grey Parrots would be detected increased, both in terms of the number of birds detected and the numbers recorded in a series of point counts. The goal was to use a radius as large as possible, but within which detection of all parrots could be reasonably assured, in both open and dense vegetation types. Thus the $25 \mathrm{~m}$ radius was a compromise between the open and closed habitats.

The study area covered the whole of the southern part of Cameroon where rainforest exists (Figure 1). Sample points were selected randomly on each path in protected or nonprotected areas, to ensure that a cross-section of the major vegetation types in the geographical range of the Grey Parrot was sampled.

Accurate distance measurements between counting points are very important in this method since bird detection is associated with a certain distance. All walked distances were measured using two pedometers (Scanner Mark II) by two observers. Each pedometer was adjusted to the normal strides of the observer at the beginning of each data collection session. All members of the research team were drilled on distance estimation prior to point data collection to reduce the bias of distance estimates in the field. The distance between two adjacent counting points on the same path was $250 \mathrm{~m}$, decided after considering the rate of parrot encounters $/ \mathrm{km}$ and the associated vegetation types and structures. This distance was chosen to ensure that detection from different points remained statistically independent [23] and it represented a compromise between sample size and parrot conspicuousness in the dense tropical rainforest. A $1 \mathrm{~km}$ path length selected for data collection produced 4 points with $250 \mathrm{~m}$ between them and this was considered 
reasonable to enhance the rate of parrot encounters per counting session. For each study site, a minimum of $10 \mathrm{~km}$ was covered, thereby producing a minimum of 40 counting points per site per visit. The 32 sample sites in the whole country produced a minimum of 1280 counting points per sampling round. It is known that activity patterns of Grey Parrots change with seasonality $[24,25]$, so we collected data in both the dry and wet seasons. Both dry and rainy seasons data were collected separately each per year, with a minimum of 2560 samples of counting points per year $([2560]=1280 \times 2$ wet/dry season counts/year $)$ and carried out during 4 years (2008-2011 amounts to $2560 \times 4=10240$ counting points). In this paper we limited our results to the mean of combined yearly parrot counts.

The duration of data recording at a point was 10 minutes. A longer duration was considered more likely to record birds making long movements from previously sampled points, which would invalidate the critical assumptions of the method. Shorter duration of 5 minutes would not have allowed sufficient time to detect parrots that were not inconspicuous at counting points, so 10 minutes was taken as the best compromise between the longer and shorter durations.

Detection between count points was recorded as "present" (+), but these data were not used in the final calculation of population size, being only used to show the presence/absence of birds at the sampling site. Sightings of flying birds and auditory detection were not included in the dataset but were simply recorded as present at the site. Two or more observers made individual counts and then compared their results before recording a final total, so as to reduce counting bias. To minimize variations associated with indices of abundance, the counting of parrots was conducted at times when there was little change in conspicuousness of the birds [14]. Generally, Grey Parrots are known to be more active in the morning and evening than around midday and in the afternoon $[26,27]$. Data collecting periods were therefore standardized to fit within peak periods of activity of the birds ( $0600 \mathrm{~h}-1000 \mathrm{~h}$ and $1400 \mathrm{~h}-1800 \mathrm{~h})$.

2.4. Data Analysis. Geographic coordinates (longitude and latitude) and altitude of each sampled site and all parrot detection points were registered with a Global Positioning System (GPS). This information was later downloaded into ArcGIS software and analysed for distribution on a topographic map of Cameroon. Satellite vegetation data on Cameroon were obtained from various databases. The data consisted of aboveground vegetation biomass $(\mathrm{Mg} / \mathrm{Ha}$ biomass), Cameroon ecoregions, and vegetation (land cover) datasets. Each vegetation dataset was analysed and arranged on the Cameroon topographic map in various layers. Finally, the parrot detection points were arranged in a layer, which was superimposed on each vegetation map to come out with various distribution maps of the bird.

To calculate Grey Parrot densities and numbers for each region of the country, the following formula for point counts within and beyond a fixed radius [22] was used:

$$
\text { Density }=\log _{e}\left(\frac{n}{n_{2}}\right) \times \frac{n}{m}\left(\pi r^{2}\right),
$$

where $n$ is the total number of birds counted, $n_{2}$ is the number beyond the fixed radius, $n_{1}$ is the number counted within the radius $(r)$ so that, $n=n_{1}+n_{2}, m$ is the total number of counts, $r$ is the fixed radius.

Various parrot densities were calculated using the above formula. Total surface area (size) occupied by rainforest within the current range of the parrot in each region was obtained from the Ministry of Forest and Wildlife, Cameroon [28]. Similar information was also obtained on the total surface area of each region of the country. Parrot densities were obtained from the formula

$$
\text { Density }=\frac{\text { Number of individual animals }}{\text { Surface area occupied }} \text {. }
$$

From this equation, we obtained the population size of parrots from the densities of each region. Confidence limit (CL) at $95 \%$ was used to calculate the lower and upper limits to the population size per region. Final datasets were synthesized and analysed using relevant statistical packages (SPSS, Map Info, and Microsoft EXCEL).

\section{Results}

3.1. Range Delimitation. The historic range of the Grey Parrot is limited to the rainforest and associated transitional vegetation of Cameroon's greenbelt, which dominates the grand southern part of the country. This area includes the low and highland rainforests and wooded savannah vegetation. The range includes major parts of the Southwest, Littoral, South, Centre, and East Regions and small parts of North West and West Regions (Figure 1). It harbours about seventeen protected areas, eight important bird areas (IBAs) outside protected areas [13], and seven other sites not yet designated for conservation.

The Grey Parrot was rare or completely absent in some parts of the range where it used to occur in abundance some 30 to 50 years ago. This means that the historic range is being fragmented and deforested through agricultural activities, urbanization, infrastructural development, and timber exploitation, especially around major urban areas and villages. What remains of this original vegetation and how the parrot was distributed in it are shown in Figure 2. A close correlation of parrot detection points with aboveground vegetation biomass is evident in Figure 2. The parrot's current range encompasses the southern part of the country as in historic times. The Grey Parrot is roughly and evenly distributed within the current range in Cameroon, with severe habitat fragmentation and gradual contractions in many parts of it (Figure 2) and especially the western part of the range.

3.2. Distribution according to Ecological Regions. Data were further analysed to show the distribution of the Grey Parrot with respect to the ecological regions of Cameroon (Figure 4). There are seven ecoregions in the country and three of them harbour the Grey Parrot in significant numbers. In order of decreasing abundance of Grey Parrots, they are Northwestern Congolian Lowland Forest, which is a typical lowland rainforest; Atlantic Equatorial Coastal Forest, which is made up 


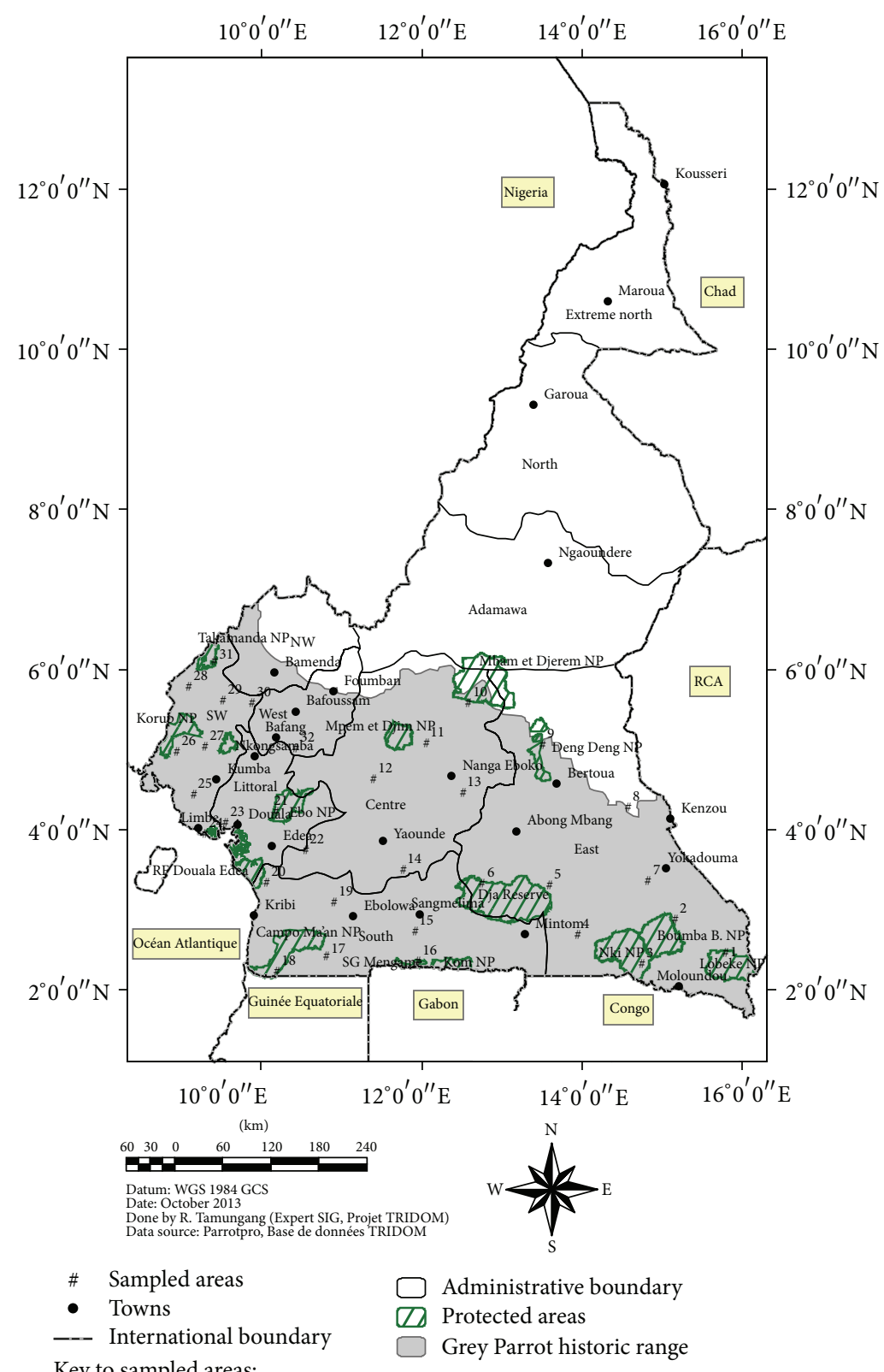
Key to sampled areas:
(1) Lobeke NP
(2) Boumba Bek NP
(3) Nki NP
(4) Ngoila Environs
(5) Lomie Environs
(6) Dja BR
(7) Yokadouma Ens
(8) Batouri Ens
(10) Mbam/Djerem NP
(11) Ngambe Tikar Ens
(9) Deng Deng NP
(13) Nanga Eboko Ens
(14) Mbalmayo FR
(12) Bafia Ens
(16) SG Mengame
(17) Ma’an Ens
(15) Integral ER
(19) Lolodorf Environs
(20) Douala Edea FR
(22) Lac Ossa W R
(23) Mt Cameroon NP
(18) CampoMa’an NP
(25) S. Bakundu FR
(28) Ejagham FR
(26) Korup NP
(21) Yabassi Ens
(31) Takamanda NP
(29) Nta Ali FR
(24) Dibombe-Mabobe FR
(27) Rumpi Hills WR
(32) Santchou WR
NP: National Park
WR:Wildlife Reserve
FR: Forest Reserve
SG: Gorilla Sanctuary
(30) Bayang-Mbo WR
BR: Biosphere Reserve
Ens: Environs

Figure 1: Historic range of the Grey Parrot in Cameroon, in relation to sampled areas, protected areas, urban centres, and administrative boundaries. 


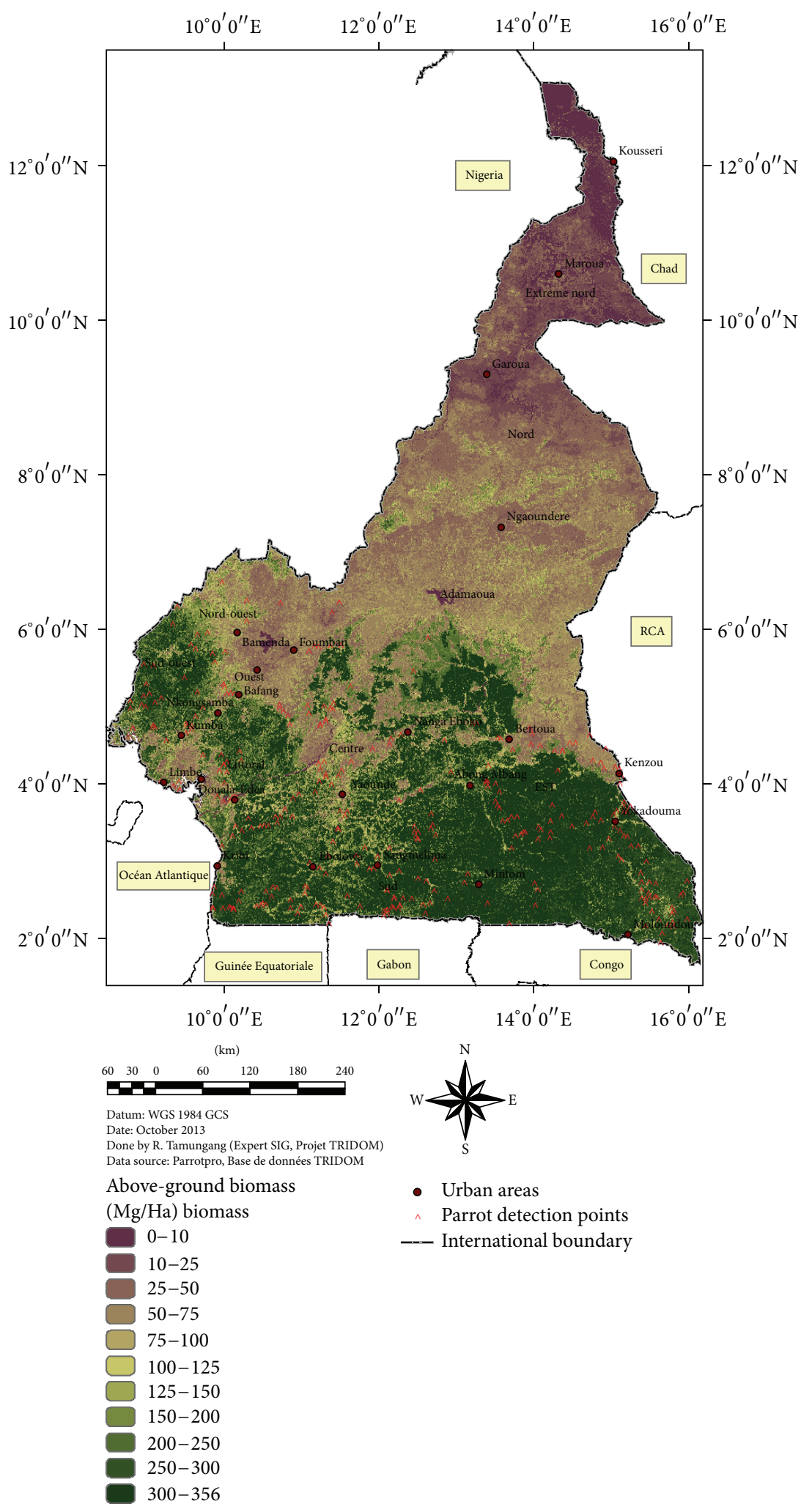

FIGURE 2: Current distribution of Grey Parrots in Cameroon in relation to parrot detection points and aboveground vegetation biomass. 


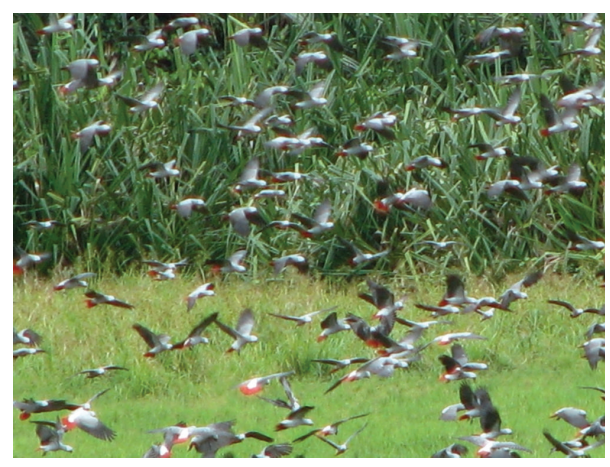

FIGURE 3: Grey Parrots congregate at a feeding site in a swampy area in the rainforest of Southeastern Cameroon.

predominantly of mangrove swamp forest (Figure 3); and the Cross-Sanaga-Bioko Forest, which is predominantly made up of a mixture of lowland and highland rainforest.

Two ecoregions that share boundaries with the Grey Parrot's range identified above were the Cameroonian highland forest and the Northern Congolian Forest-Savannah Mosaic. These ecoregions formed an ecotone with the two vegetation types and could provide rare habitat resources such as food diversity and nest sites for the parrot. A more detailed look at the rainforest (Figure 4) showed that it covers the low coastal region (parts of Littoral, Southwest, and South) and a large part of the southern plateau (parts of Centre, East, Southwest, Littoral, and West Regions). This vegetation type is also known as evergreen forest. It is luxuriant and has a continuous canopy of leaves, thereby forming a carpet-like structure when viewed from above. It has tall trees about $40 \mathrm{~m}$ high which struggle for sunlight all the time. In places where light does not reach the ground, it becomes dark and gloomy and sometimes with scant undergrowth. The Grey Parrot preferred to use more of the open parts of the vegetation (Figure 3) than the closed vegetation parts. There were many types of trees with different heights and sizes in this forest type. Some of the trees had broad and closed canopy with opened understory. Some trees of the rainforest shed their leaves at a particular period of the year. This forest provided many tree species to the economy, medicine, and traditional domains and also serves as a valuable food source to the parrot.

3.3. Distribution according to Vegetation Types. Between the equatorial and tropical belts is a transitional vegetation cover with characteristics similar to both rainforest and savannah (Figure 5). In most of the cases, this zone was made up of semideciduous or mixed forest containing some evergreen and some deciduous trees. This transitional zone was more or less tampered with by both human activities and bush fires. From the south to the north, the rainforest gradually gave way to savannah except in the mountainous regions of the southern part of country.

Mangrove forest with its specific flora (Figure 4) bordered the rainforest, mostly in coastal wetland areas. From one end, it stretched within two main regions which ran from the coast of Rio-del-Ray and extended to the foot of Cameroon Mountain and to the coast. At the other extreme, it ranged from Bimbia through Tiko to Modeka and further to Douala or Wouri Estuary. The mangrove forest was characterised by mangrove plants (Rhizophora mangle), swamps (Figure 3), creeks, estuaries, and raffia palms. The mangrove trees generally possess breathing roots that were stilted from mud and were saltwater tolerant. This vegetation is known to be an exceptionally rich habitat for a variety of fauna and is a nursery to most aquatic and semiaquatic species. Many Grey Parrots used the mangroves for roosting and other activities, and parrots were observed in the mangroves of Tiko, Wouri Estuary, and Mouanko and in Campo. Mangrove forest in Cameroon was threatened by frequent harvesting for socioeconomic benefits such as fuel wood, fencing, and house roofing.

Adjacent to the mangrove was the rainforest vegetation, which could be further subdivided into two major vegetation types: Evergreen Broadleaf Forest and Deciduous Broadleaf Forest. These vegetation types occupied major parts of the East, Centre, South, and Littoral Regions and harbour large populations of Grey Parrots. Minor parts of this vegetation were found in the South West, West, and Northwest Regions. The third vegetation type (woodland savannah) harboured minor populations of Grey Parrots. It is also known as the Guinea Savannah and was a transitional vegetation type between the rainforest and the grassland. Guinea Savannah vegetation was prominent around Kenzou through Garoua Boulai to Meiganga, North of Nanga Eboko, and Bangante through Tonga to Bafia, Ngambe Tikar through Bankim to Mayo Banyo, and from Magba towards Foumban (Figure 5). The continuous fragmentation of the historic range of the Grey Parrot has influenced the dispersal pattern of the species.

In a similar study, Global Forest Watch (GFW), Cameroon, [2] estimated the amount of vegetation types within the rainforest zone in Cameroon (Table 1). According to the GFW study, the mangrove and the swamp forest represented $0.8 \%$ of each vegetation type in the country. Therefore the mangrove and swamp forests represent $1.6 \%$ of the rainforest zone. However, $0.2 \%$ (44 sq. $\mathrm{km}$ ) of the mangrove was found in protected areas, whereas there was no swamp forest in protected areas (Table 1). The upper montane vegetation was infrequently used by the Grey Parrot and represented only $0.03 \%$, which is comparatively a negligible amount. The bulk of the vegetation matrix was taken by the lowland evergreen and broadleaf rainforest (Table 1), whereas the deciduous and semideciduous and broadleaf rainforest had the highest percentage $(10.7 \%)$ of the rainforest zone. These two vegetation types were most used by the Grey Parrot (see Figure 4). The two latter vegetation types jointly represented $16.1 \%$ of the total forest area in the country. Furthermore, the deciduous and semideciduous and broadleaf rainforest types jointly represented $67.1 \%$ of protected areas in the country. Sparse trees $(8.3 \%)$ were rarely used by the parrot except in food rich patches similar to those of the rainforest as found around Makenene and Ndikinemiki. A relatively significant quantity of sparse trees (29.5\%) was present in protected areas (Table 1). Degraded 


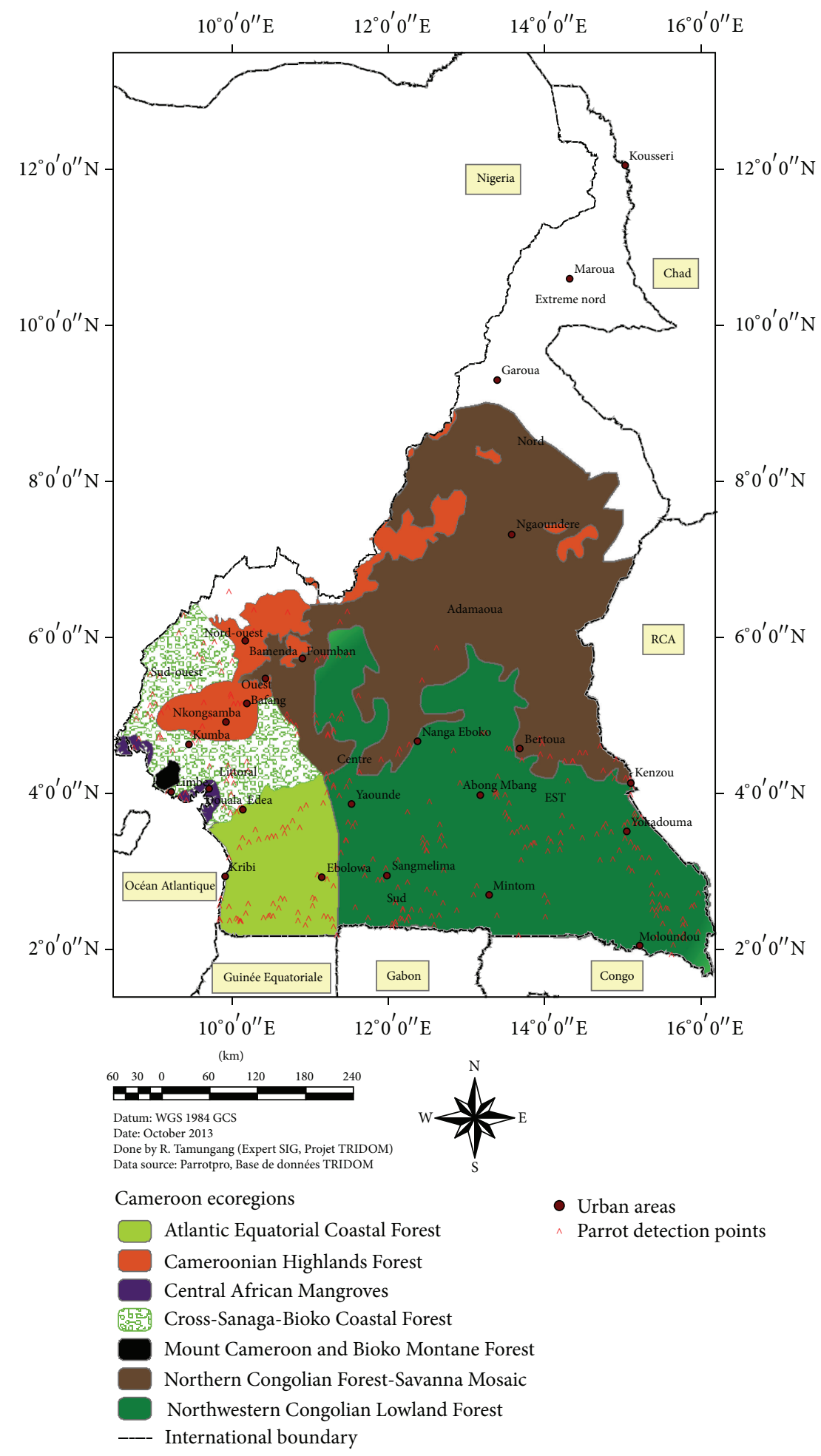

FIGURE 4: Contemporary distribution of Grey Parrots in ecoregions of Cameroon using parrot detection points.

vegetation was made up of mainly cropland, bare ground, and urban areas. The Grey Parrot was a frequent visitor to croplands especially at sites that still had clusters of tall trees as favourite sources of food, such as the oil palm tree (Elaeis guineensis).
3.4. Range Distribution according to Elevation and Protected Areas. Elevation points above sea level were recorded at all parrot detection points. Only samples of the elevation points that show the range of elevation in each region of the study area are presented in this paper. The points ranged 


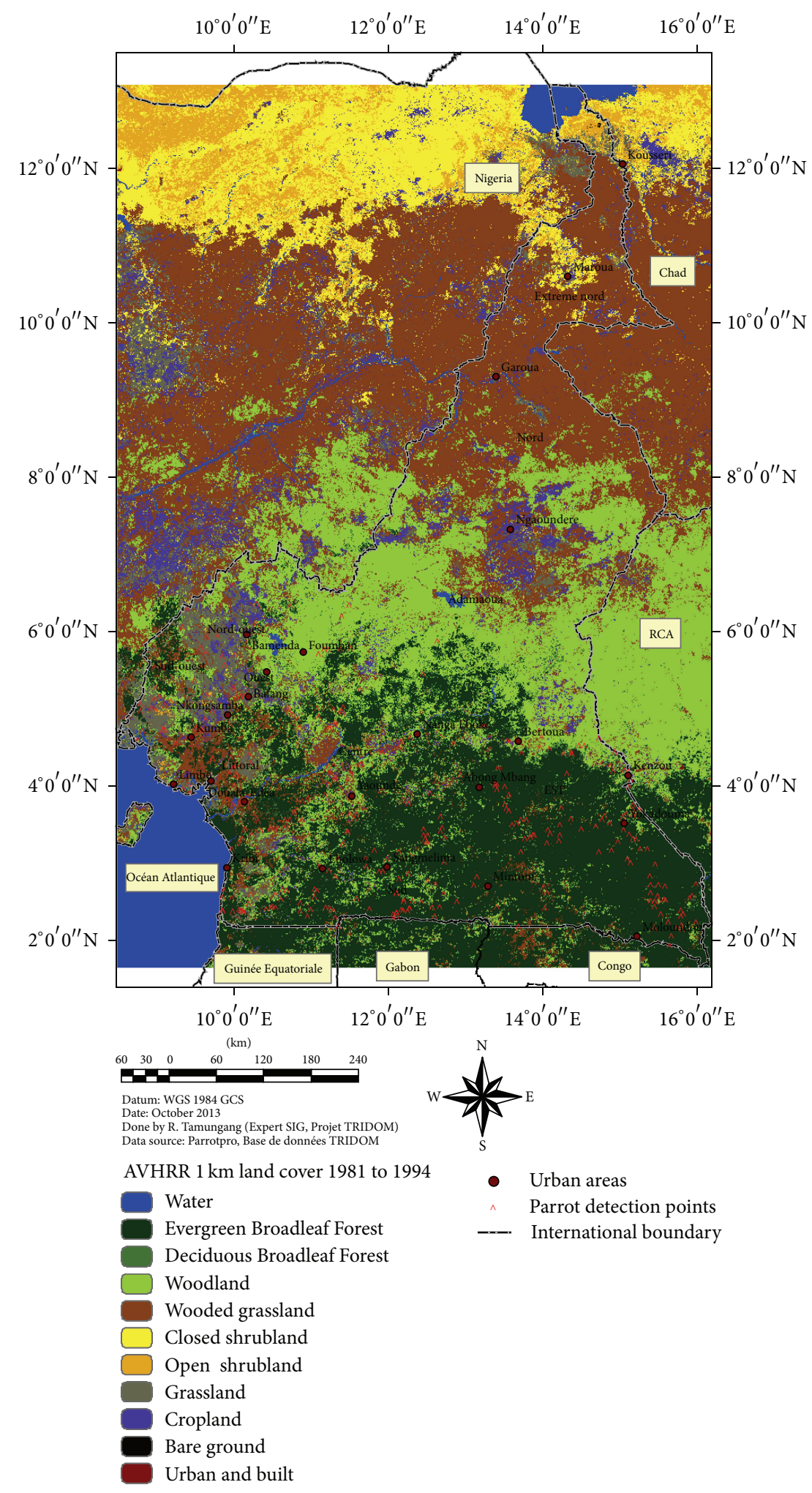

FIgURE 5: Current distribution of Grey Parrots in vegetation cover in Cameroon in relation to parrot detection points. 
TABLE 1: Major vegetation types within the current range of the Grey Parrot in relation to total forest zone and protected areas [3].

\begin{tabular}{|c|c|c|c|c|}
\hline Vegetation types & $\begin{array}{c}\text { Total forest area } \\
\text { (square } \mathrm{km} \text { ) }\end{array}$ & $\begin{array}{c}\text { Percentage of } \\
\text { total area }\end{array}$ & $\begin{array}{c}\text { Protected area } \\
\text { (square } \mathrm{km})\end{array}$ & $\begin{array}{c}\text { Percentage of total } \\
\text { protected area }\end{array}$ \\
\hline Mangrove & 2275 & $0.8 \%$ & 44 & $0.2 \%$ \\
\hline Swamp Forest & 2208 & $0.8 \%$ & 0 & $0.0 \%$ \\
\hline Montane & 3188 & $1.1 \%$ & 6 & $0.03 \%$ \\
\hline $\begin{array}{l}\text { Lowland Evergreen } \\
\text { Broadleaf Rainforest }\end{array}$ & 163582 & $56.4 \%$ & 11354 & $63.6 \%$ \\
\hline $\begin{array}{l}\text { Deciduous and } \\
\text { semideciduous } \\
\text { Broadleaf Rainforest }\end{array}$ & 31111 & $10.7 \%$ & 630 & $3.5 \%$ \\
\hline Sparse trees & 24163 & $8.3 \%$ & 5259 & $29.5 \%$ \\
\hline Degraded & 63438 & $21.9 \%$ & 560 & $3.1 \%$ \\
\hline Total & 289965 & $100.0 \%$ & 17853 & $100.0 \%$ \\
\hline
\end{tabular}

from Lake Mbouli and Mouanko with $5 \mathrm{~m}$ in the Littoral Region, Mangroves of Ekondo-Titi with $7 \mathrm{~m}$ in the Southwest Region, Nkoelon Village $(16 \mathrm{~m})$ in Campo through Eseka $(228 \mathrm{~m})$ in the Centre Region, Mebang Village $(637 \mathrm{~m})$ in the South Region, Ndikinemiki $(829 \mathrm{~m})$ in the Centre Region to Nkolakie Village (1038 m) in the Centre Region. Most parrots were sighted below the elevation of $650 \mathrm{~m}$, usually in lowland rainforest.

The status of the Grey Parrot and its habitat in state owned protected areas in the contemporary range of the parrot were evaluated and presented in Table 2 .

The surface areas of each protected area were obtained from the Interactive Forest atlas of Cameroon [29]. There are three major categories of state owned protected areas in Cameroon, namely, faunal reserves, national parks, and sanctuaries. Each of the categories has a slightly different management status from each other. For example, all wildlife resources are totally protected in national parks and, as such, security measures are higher in them than in reserves and sanctuaries. Such resources can only be exploited with permission from designated management authorities of the government. The Grey Parrot is therefore totally protected in national parks and partially protected in reserves and sanctuaries. However, Dja Reserve is a UNESCO Biosphere Reserve and therefore gains total protection equivalent to that of a national park (Table 2). At the national level, the parrot gained total protection in 16 national parks and one reserve out of the 22 protected areas in the contemporary extent of the range. Outside protected areas, the parrot is not protected by formal security measures, but the 1994 Forestry and Wildlife Law [30] prohibits the trapping of the bird outside protected areas, except with a legal permission. The protected areas were distributed in all the ecoregions and administrative regions of the study area, covering a total area of 3165488 ha $\left(3165.49 \mathrm{~km}^{2}\right)$. The parrot was present in 21 of the 22 protected areas, with the exception of Santchou Reserve where it was extinct due to habitat degradation and protracted poaching.

Each protected area designated with partial habitat status might not harbour the Grey Parrot in some of its parts due to the presence of savannah and grassland which do not attract the parrot. In some cases, the difference in habitat type in a protected area might be due to degradation from past socioeconomic pressures on the habitat or because that part of the protected area was on a relatively higher elevation than other parts. Generally, high elevations brought about changes in vegetation composition and structure. For example, most of the Grey Parrots were detected below the elevation $800 \mathrm{~m}$ in the montane protected areas. In all, $54.6 \%$ of the protected areas were completely covered with rainforest (Table 2 ). The parrot therefore had more habitat resources for exploitation in those protected areas than those with partial rainforest.

3.5. Proportions of Lost Habitat. The contemporary range of the parrot has not drastically contracted but has been reduced through fragmentation and deforestation in all regions. Fragmentation was observed not only in logged forest concessions, farmland, and human settlements, but also in some parts of protected areas which were encroached with farms and human settlements. For example, villages were observed in the Korup National Park and the Santchou Reserve pending government resettlement activities to the support zone of the protected areas. All the regions with parrot populations had at least $20.40 \%$ of surviving rainforest (Table 3).

The East and South Regions had the largest and equivalent percentages of forest, although they do not have the same surface area. It should be noted that the forest in the latter is smaller than that in the former. In the Centre Region, it should be noted that Yaoundé, the national capital of Cameroon, and other urban areas have taken up a lot of former forest. Similar deforestation and fragmentation trends were observed in the Littoral and South West Regions, but the latter has more industrial agroplantations than the former. Table 3 therefore compares forest cover available for parrot conservation policy formulation.

3.6. Regional Abundance and Conservation Status of the Grey Parrot. The contemporary range of the parrot extends to seven regions of Cameroon, but five of the regions had Grey Parrots in significant quantities (Table 4). The North West and West Regions had very low parrot populations as a result of extensive exploitation pressures of the forest and 
TABLE 2: Status of the Grey Parrot in national protected areas within the contemporary range of the bird species.

\begin{tabular}{|c|c|c|c|c|c|}
\hline $\begin{array}{l}\text { Protected area } \\
\text { category }\end{array}$ & Name of protected area & Surface area (ha) & $\begin{array}{c}\text { Parrot population } \\
\text { status }\end{array}$ & Parrot habitat status & $\begin{array}{c}\text { Parrot protection } \\
\text { status }\end{array}$ \\
\hline \multirow{4}{*}{ Faunal reserves } & $\mathrm{Dja}$ & 526000 & Present & Complete & Total \\
\hline & Doula-Edea & 160000 & Present & Complete & Partial \\
\hline & Lac Ossa & 4000 & Present & Partial & Partial \\
\hline & Santchou & 4000 & Extinct & Partial & Partial \\
\hline \multirow{16}{*}{ National parks } & Boumba Bek & 238255 & Present & Complete & Total \\
\hline & Campo Ma'an & 264064 & Present & Complete & Total \\
\hline & Deng Deng & 58091 & Present & Complete & Total \\
\hline & Ebo & 141706 & Present & Complete & Total \\
\hline & Kom & 67838 & Present & Complete & Total \\
\hline & Korup & 125900 & Present & Complete & Total \\
\hline & Lobeke & 217854 & present & Complete & Total \\
\hline & Mbam et Djerem & 416512 & present & Partial & Total \\
\hline & Mefou & 1044 & Present & Partial & Total \\
\hline & Mont Cameroon & 64677 & Present & Partial & Total \\
\hline & Monts Bakossi & 29320 & Present & Partial & Total \\
\hline & Rumpi Hills & 45675 & Present & Partial & Total \\
\hline & Mpem et Djim & 97480 & Present & Partial & Total \\
\hline & Ndongore & 233400 & Present & Partial & Total \\
\hline & Nki & 309362 & Present & Complete & Total \\
\hline & Takamada & 67599 & Present & Partial & Total \\
\hline \multirow{2}{*}{ Sanctuaries } & Bayang-Mbo & 66000 & Present & Complete & Partial \\
\hline & Mengame & 26711 & Present & Complete & Partial \\
\hline
\end{tabular}

TABLE 3: Comparison of forest areas as a percentage of total surface area of regions in Cameroon.

\begin{tabular}{lccc}
\hline Region & Forest area $/ \mathrm{km}^{2}$ & $\begin{array}{c}\text { Total area of } \\
\text { region } / \mathrm{km}^{2}\end{array}$ & $\begin{array}{c}\text { \% forest in total surface } \\
\text { area of region }\end{array}$ \\
\hline Centre & 14058.47 & 68915.50 & 20.40 \\
East & 62559.15 & 109595.57 & 57.08 \\
Littoral & 6973.58 & 20134.06 & 34.64 \\
South & 27275.43 & 47786.22 & 57.08 \\
South West & 9893.17 & 24968.81 & 39.62 \\
\hline
\end{tabular}

TABLE 4: Regional distribution of Grey Parrot population size and conservation status.

\begin{tabular}{lcc}
\hline Region & Grey Parrot population size & Conservation status \\
\hline North west & Very low & Class A \\
West & Very low & Class A \\
Littoral & $2720-4254$ & Class A \\
Southwest & $4452-19292$ & Class B \\
Centre & $9700-11106$ & Class B \\
South & $39277-54551$ & Class C \\
East & $108227-162028$ & Class C \\
\hline
\end{tabular}

also because larger parts of the regions have savannah and grassland vegetation. The Littoral and Southwest Regions had relatively low parrot populations, while the South and the
East Regions had high populations, and the Centre Region occupied a median position (Table 4 ).

Regional means ranged from 3,487 parrots in the Littoral to 1351,275 parrots in the East Regions. The South and the East Regions had the highest parrot populations in the country.

We adopted the Cameroon classification system of wildlife threats (found in the 1994 Forestry and Wildlife Law [30]) to describe the regional conservation status of the Grey Parrot (Table 4). Class A was generally used to describe a wildlife population that was threatened by extinction. It was strictly forbidden to carry out any harvesting activity on such a population. In class $\mathrm{B}$, the wildlife population was vulnerable to threat, but a few individuals of the population could be harvested under administratively supervised conditions, along with population development programmes. Restoration programmes were needed to bring the populations up to abundance levels in classes A and B. 


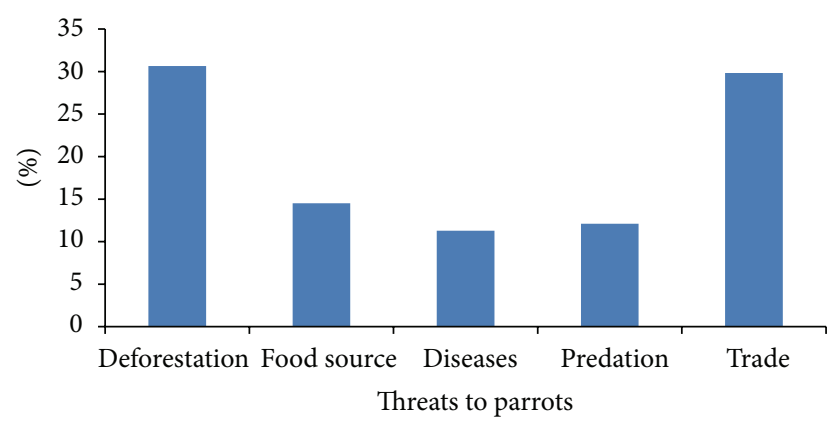

Figure 6: Percentages of threats to parrot distribution and abundance in Cameroon.

In class $\mathrm{C}$, the wildlife population was abundant and as such, legal harvesting/hunting could be sustainably carried out but not above the carrying capacity of the population. According to the regional conservation status (Table 4), parrots could be legally harvested for commercial purposes only in the South and the East Regions. Controlled legal harvesting could be carried out in the Southwest and the Centre Regions for local consumption. No harvesting should be permitted in North West, West, and Littoral Regions. All illegal harvesting of the Grey Parrot in any of the regions was punishable as defined by the Cameroon Wildlife Law [30]. The distribution and abundance of the Grey Parrot reflected the quantity of forest currently surviving in each region of the country.

3.7. Threats to the Distribution and Abundance of Parrots. Major threats to sustainable parrot conservation in Cameroon are directly linked to anthropogenic pressure either directly on the parrot or on its habitat. Five major threats to the parrot (Figure 6) were identified from questionnaire sampling: forest deforestation, trapping for food, diseases, trapping for trade, and predation by wild animals. Irrespective of region, deforestation and trapping for trade were the major threats with a combined percentage of $63 \%$.

Trapping for food was comparatively rare ( $15 \%$ occurrence), but it was estimated that about $33.3 \%$ of the parrots die in the course of trapping and exporting them. Diseases and predation have been recorded in the field, but their levels are sustainable and are not a cause for concern now. Deforestation and trade are factors which are of urgent concern for the survival of parrots in Cameroon. At regional level, results showed that deforestation in the East and, South accounted for $34.6 \%$ and $26.4 \%$, respectively, and these values gave a total of $61 \%$. This means that if the deforestation problem is tackled only in these two regions, $61 \%$ of it is already tackled in the whole country. Similar trends apply for trade in the South and the East Regions with the two carrying 54.1\%. These two regions are paramount if Cameroon must move forward in sustainable parrot conservation.

Habitat and trade threats are the frontline threats to sustainable parrot conservation in Cameroon. The rainforest is the most exploited habitat in the country due to its richness in biological diversity.

\section{Discussion}

4.1. Association between Vegetation Types and Parrot Distribution. As one of the geographical range states for Grey Parrots, Cameroon's forests are mostly found south of $6^{\circ} 30^{\prime}$ north latitude and represent the northern limit of the Congo Basin forests. The country possesses diversified ecosystems, which contain examples of most floral ecosystems found on the African continent [31]. The current distribution results show that Grey Parrots are widespread in the southern parts of Cameroon where most of the remaining rainforest still survives. Grey Parrot distribution is restricted and thus populations are small in the middle areas of the contemporary range where forest stands have been fragmented or lost to urban infrastructure and agroindustrial plantations. The species is presently absent in the northern part of Cameroon which is dominated by woodland in the north and wooded grassland in the far north. Cameroon's contemporary vegetation matrix varies greatly with its major ecological regions, both of which have influenced the historical and current distributions and abundance of Grey Parrot populations by providing a plethora of habitat resources.

The distribution of the Grey Parrot within the various habitat types presents a reliable basis to explain the current observed trends. Factors within any given habitat act either singly or together to influence the presence of wildlife species within the habitat $[5,10]$. The vegetation distributional maps show that the Grey Parrot mostly inhabits lowland rainforest areas within Cameroon, with elevation from Limbe $(5 \mathrm{~m})$ through Ndikinemiki ( $829 \mathrm{~m}$ ) up to Nkolakie (1038 m). Whin these areas, the Grey Parrot generally prefers a zone with patches of primary and secondary vegetation up to the elevation of $650 \mathrm{~m}$. For example, more Grey Parrots were sighted within the support zone of the Korup National Park in the southwestern Cameroon than in the park itself. This support zone is characterised by heterogeneous secondary forest, and it is rich in food sources for Grey Parrots [24]. In the Lobeke National Park in the Southeastern part of the country, more Grey Parrots were recorded inside the park area than outside. Most of the park area is made up of mixed vegetation brought about by frequent mixing of the top soils by large mammals such as elephants and buffaloes. Within Mengame Gorilla Sanctuary in the extreme south of the country, an equal number was recorded in the park as outside. Similarly, in the Budongo and Mabira Forest Reserves in Uganda, Grey Parrots were encountered at higher numbers in disturbed or secondary forest areas, where fruiting trees were abundant [32]. In contrast, in the Kakamega forest in Kenya, the Grey Parrot was not recorded in areas of the forest that had been fragmented and degraded, except in a monoculture stand of Acrocarpus fraxinifolius [33].

In addition, parrots were also found in some areas characterised by plantation cultivation. One of such plantations often used by Grey Parrots was the oil palm plantation [26, 34]. Grey Parrots mostly feed on the fruits of the oil palm or use their fronds as roosting sites [25]. Grey Parrots were also found near water bodies and marshy areas as well, especially in the South, Southwest and East Regions of Cameroon. Grey 
Parrots have been reported in shrub vegetation in São Tomé and Principe, which were utilised by the birds for nesting [35].

Floral composition within the different habitats found in Cameroon presents itself as the strongest factor that could have influenced the current distribution of the Grey Parrot. For example, floral composition determines the availability of food for bird species [16]. The "food basket" of Grey Parrots in the Korup National Park consisted of 14 food tree species which belonged to 12 families and the various food items were seeds, fruits, and flowers; $74.3 \%$ of these food sources were located in the support zone in the Korup National Park and $25.7 \%$ in both the support and park zones [24, 25].

\subsection{Effects of Forest Fragmentation and Deforestation on Grey} Parrot Distribution. Habitat fragmentation and deforestation are some proximate causes of Grey Parrot population depletion in many parts of Cameroon $[36,37]$. The fragmentation process involves the disruption of once large continuous blocks of habitat primarily by human disturbance such as land clearing and conversion of vegetation from one type to another [2, 38]. Major deforestation activities in Cameroon stem from socioeconomic activities. Quantitative estimates of loss can be obtained from estimates of forests exploited over the years. The United Nations Food and Agriculture Organization [38] estimated that 21.6 million hectares of forest covered Cameroon's 46.5 million hectares of land, but, by 1995 , only 19.6 million hectares remained. In a another report, FAO [3] estimated for the 1980s that close to $90 \%$ of logging occurring in Cameroon's closed forests took place in primary forests. It is estimated that $1.10 \times 103 \mathrm{~km}^{2}$ of rainforest was destroyed in Cameroon from 1981 to 1985 [4]. In another study, Myers [7] made a combined estimate of deforestation of rainforests in Cameroon, Congo, Gabon, and Zaire at $4,200 \mathrm{~km}^{2}$ in 1980 and $7,300 \mathrm{~km}^{2}$ in 1989 . Generally, commercial timber logging results in high rates of tree removal per hectare and logging roads open previously inaccessible areas to human settlements, agricultural encroachment, and hunting pressures [2].

In recent decades, Cameroon's forests have undergone extensive conversion, with half of the historic forest cover cleared for farms and settlements [28, 31]. At least $20 \%$ of remaining forests are degraded or secondary forests [29]. In addition to its direct impacts, logging can also open up forest to encroachment and the other damaging disturbance, such as wild fire. Agricultural clearing and commercial logging are the primary causes of deforestation and range reduction of the Grey Parrot in Cameroon.

The rainforest region of the country harbours the two cities (Douala and Yaounde), many towns (Kribi, Sangmelima, Kumba, Limbe, Bafia, Edea, Nanga Eboko, Mamfe, and Abong Mbang), and many small urban areas (Moloundou, Djoum, Batouri, Ambam, Campo, Eseka, Mbalmayo, and Yabassi). These urban centres have contributed immensely to the fragmentation and deforestation of the forest (Figure 2). Other parcels of land have been converted to large plantations of cocoa, coffee, rubber, banana, and oil palm. Most of these plantations are owned by the government and multinational companies that build camps around them to lodge the ever increasing number of workers of the business [27]. The construction of road networks, dams, and hydroelectricity power stations and lines destroyed many sections of the rainforest vegetation. Some of the most important wildlife parks and reserves in the contemporary parrot range are also biodiversity conservation hotspots. They include the Campo Ma'an, Douala Edea, Korup, Takamanda, Rumpi Hills National Parks, and the Dja Biosphere Reserve. They are refugia for the Grey Parrot.

At the global level, it is estimated that since historical times, the world has lost through human activity about $40 \%$ of its original 60 million $\mathrm{km}^{2}$ of forest cover. Of this value, approximately $120,000 \mathrm{~km}^{2}$ of tropical forests are destroyed each year $[5,13]$. Commercial clear-cutting and selective logging for timber are also responsible for much of this deforestation in Cameroon. However, the Government is trying to mitigate the effects of logging through regulation and programmes designed to enhance sustainable forest management, but field enforcement measures are often poor, and illegal logging dominates in some regions.

We estimated the extent of the current Grey Parrot range as a percentage of the whole country as $25.4 \%$ and as a percentage of the regions with rainforest as $44.5 \%$. We further estimated the historic Grey Parrot range in Cameroon lost over the years as $55.5 \%$ in 2011 . The estimated extent of the range of the Grey Parrot in Africa by CITES in 2006 [11] was $3,000,000 \mathrm{~km}^{2}$. We calculated the contemporary parrot range on Cameroon as a proportion of CITES' range estimate as $9 \%$.

The African Grey Parrot is a very mobile bird in the rainforest environment; it moves intensively in search of rich food patches and suitable nesting sites $[6,39]$.

The home range of the Grey Parrot is threatened in Cameroon by socioeconomic activities that destroy tree species used by the bird [39]. Habitat fragmentation and deforestation of the range imply that:

(i) the bird is more exposed and hence vulnerable to trappers and predators,

(ii) it has to travel longer distances to look for food and nest cavities, thereby being exposed to more trappers and/or predators,

(iii) the bird may be forced to migrate to richer habitats elsewhere and this may be even out of the country.

Socioeconomic activities (such as agroforestry) that preserve the life of tree species known to be frequently used by the parrot (such as Ceiba pentandra, Terminalia superba, Melia excels, Pycnanthus angolensis, etc.) especially in the support zones of protected areas can be carried out with parrot/wildlife conservation programmes. The felling of trees destroys the nesting, feeding, and roosting sites of Grey Parrots. Together, these negative factors are causing population declines and limits to population distribution of Grey Parrots in Cameroon.

4.3. Effects of the Parrot Trade on the Distribution and Abundance of Wild Parrots. The parrot trade is big business in Cameroonian society involving the public and the private 
sectors. It begins with the rural trappers and extends to exporters in towns and cities. The Ministry of Forestry and Wildlife (MINFOF) is the major arm of the government that implements laws and regulations on the parrot trade. MINFOF works with CITES to determine export quotas of parrots for a given period. The driving force behind the trade is poverty alleviation and unemployment.

There are many methods of trapping parrots and they vary from one part of the country to the other as well as from one individual to another. Parrots are trapped all year round depending on market demands. Some of the techniques are forbidden by the Cameroon Forestry and Wildlife Law [30] for example, use of chemicals (anaesthesia and tranquillisers) on birds at roosts or feeding sites that will kill indiscriminately. Following the moratorium by CITES on parrot export from Cameroon from the 1st of January 2007, parrot traders could not export their parrots. With this difficulty, some of the illegal traders decided to use hand explosives to kill parrots that gathered in large flocks at feeding grounds. The poacher throws the explosive in the middle of the feeding flock and it explodes, killing hundreds of parrots. The poacher then gathers them, chops off the heads, legs and feathers and preserves these body parts dried. He can then sell some locally and smuggle a larger part of his booty out of Cameroon for sale. This method of catching parrots is the most dangerous ever employed in Cameroon. Felling a tree to remove juvenile birds from the nest is another destructive method that affects the parrot and its habitat negatively. It is reportedly being used when the chick is still very young and unable to fly out of the nest and also in a situation when it is not easy to climb the tree. The method is also used when the tree can be felled and used for timber. The villagers wait until they are sure that there are chicks in the nest before felling the tree. Many drivers of timber exploitation companies have reported catching young parrots when the trees are being felled in the forest.

The use of a gun with cartridges is another traditional method for getting the bird in the village. This method is mostly used by people who want to get the feathers and other body parts of the bird for traditional use or deter the birds from agricultural crop destruction.

The method used for the transportation of trapped wild parrots is a major factor that determines their survival rate for subsequent utilisation. Generally, the shorter the distance between place of trapping to the aviary, the better the success rate. Illegal trappers do not care much to reduce mortality (by taking good care of the birds before and during trapping). As such, they pack as many parrots in a cage or box as possible and place them in obscured and poorly ventilated places to pass through police checkpoints unnoticed. Some illegal trappers put live parrots in baskets covered with thick clothes or in spare tyres or use other unfavourable means to transport them to cities and towns.

Some birds die in transit from physiological stress, due to lack of food and drinking water. The trapper may introduce food items in the cage that the wild caught bird is not familiar with and it refuses to eat. There is also a possibility of the transfer of diseases when sick birds are mixed with healthy ones. People who transport parrots with their valid documents suffer lower rates of parrot mortality than illegal transporters and their parrots experience less stress and as such are healthy. Both legal and the illegal parrot trades have immensely contributed to the depletion of various parrot populations in Cameroon.

\section{Conclusion}

The historic range of the Grey Parrot was relatively larger than its contemporary range but was limited to the rainforest and associated transitional vegetation of Southern Cameroon. The range encompassed major parts of the Southwest, Littoral, South, Centre, and East Regions and small parts of North West and West Regions. Grey Parrots were roughly evenly distributed within this range. The Grey Parrot mostly preferred areas of the range at elevations of 5 to $650 \mathrm{~m}$. Out of the seven ecoregions in the country, three of them harboured Grey Parrots in significant numbers and the most preferred was the Cross-Sanaga-Bioko Forest. In these ecoregions, the Grey Parrot generally preferred a zone with mixed patches of primary and secondary vegetation. Floral composition within the different habitat types was the strongest factor that influenced the contemporary distribution of the Grey Parrot in the country.

The contemporary range has not drastically contracted but has been lost in many parts through vegetation fragmentation and deforestation. Habitat and parrot trade are the frontline threats to sustainable parrot population conservation in Cameroon. The rainforest is the most exploited habitat in the country due to its richness in biological diversity. The current rate of degradation of the range of the parrot is an indication of the general habitat loss for wildlife conservation in Cameroon. This study therefore called for urgent conservation measures for saving the range of this important bird species and associated biodiversity. Strategic programmes that will preserve the life of the Grey Parrot and its range should be a top priority of the Cameroon Government and other stakeholders in the wildlife conservation sector, for the survival of our wildlife tomorrow depends on our conservation efforts today.

\section{Conflict of Interests}

The authors declare that there is no conflict of interests regarding the publication of the paper.

\section{Acknowledgments}

Immense thanks are due to all those who assisted the research project, too numerous to mention here. Ghislain Kougoum, Francisca Khan, Edwin Penn, and Ernest Achu, all from Parrotpro Research Group, collected field data and Estella Tamungang processed the paper. This study was carried out with grants from the Ministry of Forestry and Wildlife, Cameroon; the Loro Parque Fundación, Spain; and the British Ecological Society, UK. The authors are grateful to all of them. 


\section{References}

[1] Food and Agricultural Organisation (FAO) of the United Nations, Global Forest Resource Assessment, Main Report, 2000.

[2] Global Forest Watch (GFW) Cameroon, An overview of logging in Cameroon, A Global Forest Watch Cameroon Report, World Resources Institute, Washington, DC, USA, 2000.

[3] Food and Agricultural Organisation (FAO) of the United Nations. FRA 2000 Terms and Definitions. Forest Resource Assessment Programme Working Paper number 1, Rome, Italy, 1998.

[4] G. B. Bonan, S. Levis, L. Kergoat, and K. W. Oleson, "Landscapes as patches of plant functional types: an integrating concept for climate and ecosystem models," Global Biogeochemical Cycles, vol. 1, no. 2, 2002.

[5] L. Fahrig, "Effects of habitat fragmentation on biodiversity," Annual Review of Ecology, Evolution, and Systematics, vol. 34, pp. 487-515, 2003.

[6] C. H. Fry, S. Keith, and E. K. Urban, The Birds of Africa, vol. 3, Academic Press, London, UK, 1988.

[7] N. Myers, Deforestation Rates in Tropical Countries and Their Climatic Implications, Friends of the Earth, London, UK, 1989.

[8] I. M. Pepperberg, The Alex Studies, Harvard University Press, Cambridge, UK, 1999.

[9] Convention on International Trade in Endangered Species of Wild Fauna and Flora (CITES), Psittacus erithacus, Psittacus erithacus. Twenty-second meeting of the Animals Committee, Lima (Peru), AC22, Annex 1, 2006.

[10] M. Melo and C. O'Ryan, "Genetic differentiation between Príncipe Island and mainland populations of the grey parrot (Psittacus erithacus), and implications for conservation," Molecular Ecology, vol. 16, no. 8, pp. 1673-1685, 2007.

[11] BirdLife International, "BirdLife International's review of the status of the African Grey Parrot and proposal to CITES for its conservation," in Proceedings of the 22nd Meeting of the Animals Committee, 2006, http://www.birdlife.org/action/change/cites/grey_parrot_cites_ 2006.pdf.

[12] W. J. Sutherland, Ecological Census Techniques: A Handbook, Cambridge University Press, Cambridge, UK, 2nd edition, 2006.

[13] BirdLife International, State of the World's Birds: Indicators for Our Changing World. An assessment from BirdLife Partners, 2004.

[14] D. G. Dawson, "Counting birds for a relative measure (index) of density studies," Journal of Avian Biology, no. 6, pp. 12-16, 1981.

[15] D. Hill, M. Fasham, G. Tucker, M. Shewry, and P. Shaw, Handbook of Biodiversity Methods: Survey, Evaluation and Monitoring, Cambridge University Press, 2005.

[16] G. H. Volpato, E. V. Lopes, L. B. Mendonça et al., "The use of the point count method for bird survey in the Atlantic forest," Zoologia, vol. 26, no. 1, pp. 74-78, 2009.

[17] R. L. Hutto, S. M. Pletschet, and P. Hendricks, "A fixed-radius point count method for nonbreeding and breeding season use," Auk, vol. 103, no. 3, pp. 593-602, 1986.

[18] J. Blondel, C. Ferry, and B. Frochet, "Point counts with unlimited distance," in Estimating Numbers of Terrestrial Birds, . Ralph and J. M. Scott, Eds., vol. 6 of Studies in Avian Biology, pp. 414$420,1981$.
[19] J. Bart and S. J. Earnst, "Double sampling to estimate density and population trends in birds," Auk, vol. 119, no. 1, pp. 36-45, 2002.

[20] M. G. Betts, N. P. P. Simon, and J. J. Nocera, "Point count summary statistics differentially predict reproductive activity in bird-habitat relationship studies," Journal of Ornithology, vol. 146, no. 2, pp. 151-159, 2005.

[21] S. S. Rosenstock, D. R. Anderson, K. M. Giesen, T. Leukering, and M. F. Carter, "Landbird counting techniques: current practices and an alternative," Auk, vol. 119, no. 1, pp. 46-53, 2002.

[22] C. J. Bibby, N. D. Burgess, and D. A. Hill, Bird Census Techniques, Academic Press, London, UK, 1992.

[23] R. T. Reynolds, J. M. Scott, and R. A. Nussbaum, "A variable circular-plot method for estimating bird numbers," Condor, no. 82, pp. 309-313, 1980.

[24] S. A. Tamungang and S. S. Ajayi, "Diversity of food of the Grey Parrot (Psittacus erithacus) in Korup National Park, Cameroon," Bulletin of the African Bird Club, no. 10, pp. 33-36, 2003.

[25] S. A. Tamungang, "Habitat utilisation by the African Grey Parrot (Psittacus erithacus) in Korup National Park and environs, Cameroon," Malimbus, no. 20, pp. 65-66, 1998.

[26] J. R. Clemmons, "Status Survey of the African Grey Parrot (Psittacus erithacus timneh) and Development of a Management Program in Guinea and Guinea-Bissau," Unpublished Report to the CITES Secretariat, Geneva, Switzerland, 2002.

[27] S. A. Tamungang and R. A. Cheke, Ecology and conservation of the Grey Parrot in Cameroon. Annual technical and financial progress report: field activities report from PARROTPRO, Cameroon, Unpublished report to Loro Parque Fundación, Spain, 2009.

[28] Ministry of Forests and Fauna (MINFOF), Bref Aperçu Du Secteur Forestier Camerounais, MINFOF, Yaoundé, Cameroon, 2007.

[29] World Resources Institute (WRI), "Interactive Forest Atlas of Cameroon," Version3.0, Overview Report, World Resources Institute, Washington, DC, USA, 2012, http://www.wri.org/.

[30] Ministry of Forestry and Wildlife (MINFOF), Law No 94/01 of 20 January, 1994, Fixing Forestry, Wildlife and Fishery Regimes in Cameroon, Republic of Cameroon, Yaoundé, Cameroon, 1995.

[31] Ministry of Environment and protection of Nature (MINEP), "Cameroon fourth national report to the Convention on Biological Diversity," 2009, http://www.cbd.int/doc/world/cm/cm-nr-04-en.pdf.

[32] J. B. Amuno, R. Massa, and C. Dranzoa, "Abundance, movements and habitat use by African Grey Parrots (Psittacus erithacus) in Budongo and Mabira forest reserves, Uganda," Ostrich, vol. 78, no. 2, pp. 225-231, 2007.

[33] I. Madindou and R. Mulwa, "Some conservation aspects of the African Grey Parrot (Psittacus erithacus) in Kakamega Forest, Kenya: assessment of trade and habitat destruction effects," 2008, http://www.docstoc.com/docs/79887469/GreyParrot-Report-II.

[34] P. McGowan, "Status, management and conservation of the African Grey Parrot, (Psittacus erithacus) in Nigeria," Unpublished Report to the CITES Secretariat, Geneva, Switzerland, 2001.

[35] J. B. Juste, “Trade in the gray parrot Psittacus erithacus on the island of Principe (São Tomé and Principe, Central Africa): initial assessment of the activity and its impact," Biological Conservation, vol. 76, no. 2, pp. 101-104, 1996. 
[36] UNEP-WCMC, “Species Database: CITES-Listed Species,” 2009, http://www.unep-wcmc-apps.org/isdb/CITES/Taxonomy/taxcommon-result.cfm? source $=$ animals $\&$ displaylanguage $=$ eng $\&$ Common $=21902$.

[37] World Conservation Monitoring Centre (WCMC), "Forest cover data," 2000, http://www.wcmc.org.uk/forest/data.

[38] Food and Agricultural Organisation (FAO), Forest Resources Assessment 1990: Tropical Countries, Rome, Italy, 1993.

[39] S. A. Tamungang, I. A. Ayodele, and Z. E. Akum, "Basic home range for the conservation of the African grey parrot in korup national park, Cameroon," Journal of Cameroon Academy of Science, vol. 1, no. 3, pp. 155-158, 2001. 

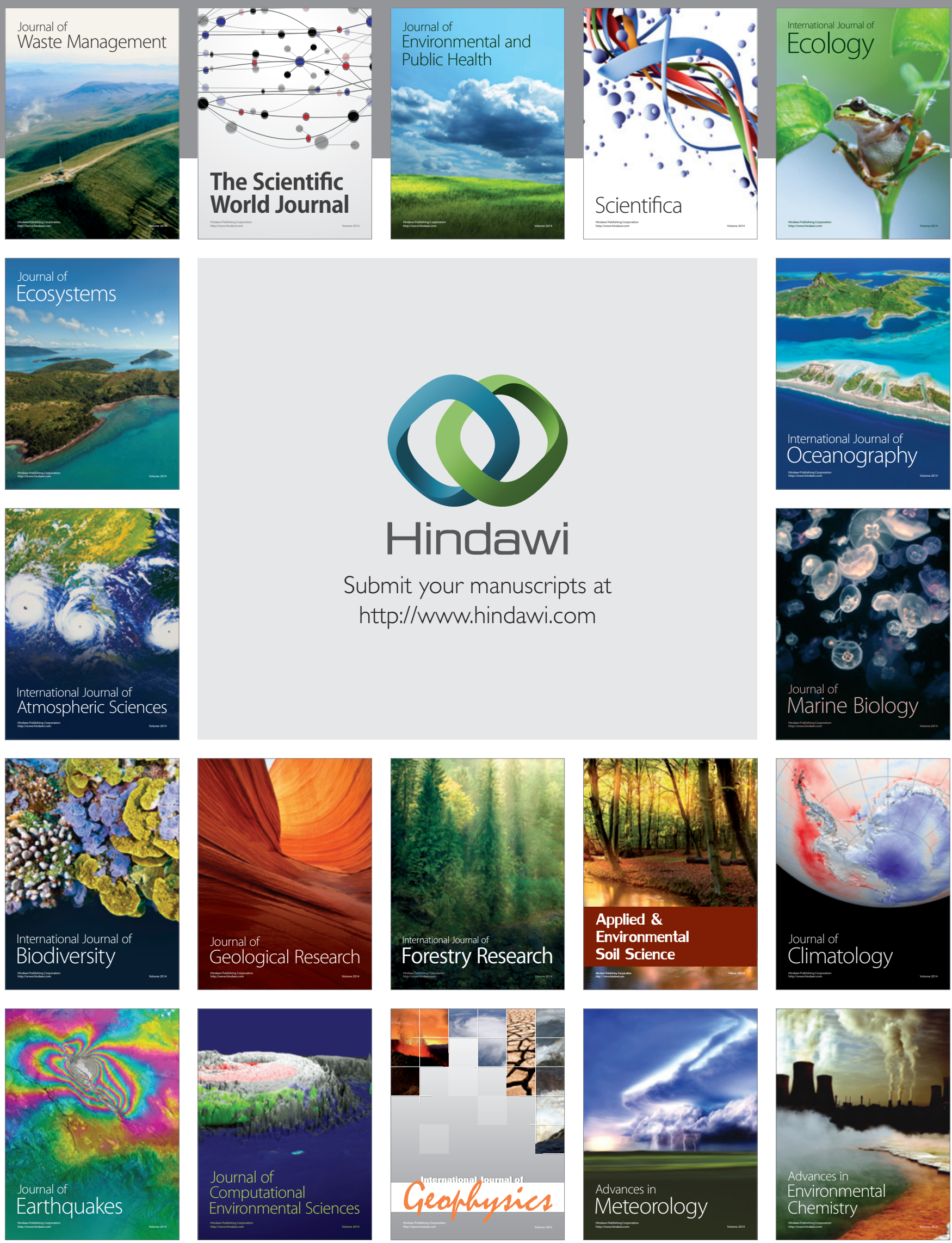